\title{
Evaluation of Antioxidant Activities of Erythrococca anomala Aqueous and Hydroethanolic Extracts from Leaves
}

\author{
Miezan Bile Aka Patrice ${ }^{1}$, Okpekon Aboua Timothée ${ }^{2}$, Kouakou Sylvain \\ Landry $^{3}$, Droucoula Guillaume Cyril ${ }^{1}$, Yapi Houphouet Felix ${ }^{1}$, \\ ${ }^{1}$ Laboratory of Biochemical Pharmacodynamics, UFR Biosciences, Felix Houphouet Boigny University, P.O. \\ Box 582, Abidjan, 22, Côte d'Ivoire. \\ ${ }^{2}$ Laboratory of Organic Chemistry and Natural Substances, UFR Sciences of Structures of Matter and \\ Technology, Felix Houphouet Boigny University, P.O. Box 582, Abidjan, 22, Côte d'Ivoire. \\ ${ }^{3}$ Department of Pharmacology, Clinical and Therapeutical Pharmacy UFR Pharmaceutical and Biologic \\ Sciences, Felix Houphouet Boigny University, P.O. Box 1679, Abidjan, 22, Côte d'Ivoire.
}

\begin{abstract}
Erythrococca anomala is an annual medicinal plant of the family Euphorbiaceae, widely used in traditional medicine in Côte d'Ivoire and sub-Saharan Africa as an anti-inflammatory, laxative and purgative. In the present work, the aim was to quantify the total phenols and flavonoids of the aqueous and hydroethanolic extracts of the leaves by the spectrophotometric method and to evaluate the antioxidant activity in vitro and in vivo of these extracts at the concentration of $200 \mathrm{mg} / \mathrm{kg}$ by the DPPH, ABTS ${ }^{+}, F R A P$ and TBARS tests. Quantitative estimation of flavonoids and total phenols showed that the extract is rich in these compounds as the hydroethanolic extract. The aqueous extract (phenols, $85 \pm 1.44 \mathrm{mg} \mathrm{EAG} / \mathrm{g}$ and flavonoids, $28.33 \pm 0.33$ $\mathrm{mg} E Q / \mathrm{g}$ ) and the hydroethanolic extract (phenols, $69.17 \pm 0.33 \mathrm{mg} E A G / \mathrm{g}$ and flavonoids, $23.23 \pm 0.83 \mathrm{mg}$ $E Q / g)$ Evaluation of the antioxidant power by the free radical scavenging methods DPPH, FRAP iron reduction, $A B T S^{+}$and TBARS ducation revealed that the aqueous extract had a higher antioxidant activity than that of the hydroethanolic extract, and neighboring Of that of quercetin and ascorbic acid.
\end{abstract}

Keywords: Erythrococca anomala, Euphorbiaceae, FRAP, TBARS, ABTS ${ }^{+}$, DPPH.

\section{Introduction}

The use of synthetic antioxidant molecules is currently being called into question due to the potential toxicological risks. Currently, new plant sources of natural antioxidants are being sought [1.2] because of their safety. Indeed, polyphenols are widespread natural compounds in plants that are increasingly important thanks to their beneficial health effects [3]. The role of natural antioxidants attracting more and more interest in the prevention and treatment of cancer, inflammatory and cardiovascular diseases [4]. They are also used as additives in the pharmaceutical and cosmetic industries [1]. Scientific methods have been developed for the extraction, identification and quantification of these compounds from medicinal plants [5. 6. 7].

Erythrococca anomala is a medicinal plant of the family Euphorbiaceae, widely used in traditional medicine in Cote d'Ivoire and sub-Saharan Africa. Phytochemical studies have revealed the presence of phenols, flavonoids, alkaloids, sterols and saponosides in leaves [8]. These secondary metabolites attract attention to play an essential role in the treatment of diseases [9]. Similarly, studies have shown that the leaves have anti-inflammatory activity [10].

In Côte d'Ivoire, the macerates of the leaves of this plant make it possible to fight against meningitis and malaria, while in Cameroon, decoctions and macerated leaves allow to treat dental pain; But used as laxatives and purgatives, make it possible to expel the worms; in Nigeria, bark is used against arthritis and rheumatism [11].

However, there is no information on the content of polyphenolic compounds and the antioxidant activity of leaves of Erythrococca anomala. This study aims to quantify the polyphenolic compounds by the spectrophotometric method, to evaluate the antioxidant activity in vitro and in vivo by the method of the trapping of the free radical DPPH, reduction of the cation ABTS ${ }^{+}$the tests of FRAP and TBARS of the aqueous and hydroethanolic extracts of leaves of Erythrococca anomala.

\subsection{Plant material}

\section{Materials and Methods}

Erythrococca anomala plant was collected in January 2015 from Yakasse-me area in the Department of Adzopé (Côte d'Ivoire). The plant was identified and authenticated by the Laboratory of Botanic, University Felix Houphouet Boigny. The authentically identified plant material (leaves) was washed and dried for 3-4 days in laboratory at room temperature. It was powdered and subjected to different extraction procedures. 


\subsection{Animal material}

Wistar albinos rats weighing 190-200 g of each sex kept for three weeks at the laboratory animal home of UFR Pharmaceutical and Biologic Sciences, University of Felix Houphouet Boigny, Côte d'Ivoire were used. The animals were maintained under standard housing conditions : temperature $\left(27^{\circ} \pm 1 \mathrm{C}\right)$, humidity $(55-60 \%)$, light/dark cycle (12:12 h) and had free access to standard rodent pellet diet and water ad libitum.

\section{Methods \\ 2.1 Preparation of extracts}

The aqueous extract is prepared from 100 grams of Erythrococca anomala leaf powder in one liter of boiling distilled water for fifteen minutes.

The solution thus obtained is filtered on hydrophilic cotton and then under vacuum with ordinary filter paper. The collected filtrate was placed in an oven at $40^{\circ} \mathrm{C}$. A dark brown dry powder was obtained for the total crude aqueous extract of Erythrococca anomala.

The Guédé-Guina method [12] was used to obtain the 70\% Erythrococca anomala hydroethanolic extract. A 70\% hydroethanolic solution $\left(\mathrm{ETOH} / \mathrm{H}_{2} \mathrm{O}, 70\right.$ : 30) was used for the preparation of The hydroethanolic extract of Erythrococca anomala in a vial. One liter of the hydroethanolic solution and $100 \mathrm{~g}$ of Erythrococca anomala powder were used for this purpose. The resulting mixture was homogenized with a magnetic stirrer for 24 hours. The homogenate is filtered on hydrophilic cotton then under vacuum. The collected filtrate was concentrated in a rotary evaporator and then placed in an oven at $40{ }^{\circ} \mathrm{C}$. for complete drying. The 70\% hydroethanolic extract of Erythrococca anomala appears in the form of a dark green paste after drying.

\subsection{Quantification of polyphenolic compounds \\ 2.2.1. Spectrophotometric assay of phenols}

Wood's method [13] was used for the determination of total phenols in aqueous and hydro-ethanolic extracts of leaves of Erythrococca anomala. A volume of $2.5 \mathrm{~mL}$ of diluted Folin-Ciocalteu reagent (1/10) was added to $30 \mu \mathrm{L}$ of extract. The mixture was held for 2 minutes in the dark at room temperature, the $2 \mathrm{~mL}$ of calcium carbonate solution $\left(75 \mathrm{~g} \mathrm{~L}^{-1}\right)$ was added.

The mixture was then placed for 15 minutes in a water bath at $50{ }^{\circ} \mathrm{C}$. and then cooled rapidly. The absorbance was measured at $760 \mathrm{~nm}$, with distilled water as white. A calibration line was made with gallic acid at different concentrations. The analyzes were carried out in triplicate and the concentration of phenols was expressed in grams per liter of gallic acid equivalent extract (g.L $\left.\mathrm{L}^{-1}, \mathrm{Eq} A \mathrm{AG}\right)$.

\subsubsection{Spectrophotometric determination of flavonoids}

The Marinova method [14] was used for the determination of total flavonoids in aqueous and hydroethanolic extracts of leaves of Erythrococca anomala. Into a $25 \mathrm{~mL}$ flask, $0.75 \mathrm{~mL}$ of $5 \%$ (w/v) sodium nitrite (NaNO2) was added to $2.5 \mathrm{~mL}$ of extract. The mixture was supplemented with $0.75 \mathrm{~mL}$ of $10 \%(\mathrm{w} / \mathrm{v})$ aluminum chloride $\left(\mathrm{AlCl}_{3}\right)$ and then incubated for 6 minutes in the dark. After incubation, $5 \mathrm{~mL}$ of sodium hydroxide $(1 \mathrm{~N} \mathrm{NaOH})$ was added and the volume was then made up to $25 \mathrm{~mL}$. The mixture was stirred vigorously before being assayed to the UV-visible spectrophotometer. The reading was made at $510 \mathrm{~nm}$. The trials were carried out in triplicate. The flavonoid content was expressed in grams per liter of quercetin equivalent extract.

\subsection{Evaluation of antioxidant activity}

\subsubsection{Investigation of antioxidant activity in vitro \\ 2.3.1.1. Preparation of ABTS}

This method is based on the capacity of the compounds present in the aqueous and hydroethanolic extracts of the leaves of Erythrococca anomala to reduce the cation radical ABTS + (2,2'-azinobis-3ethylbenzothiazoline-6-sulfonic acid). The test was performed according to the method described by Choong [15]. Radical-cation $\mathrm{ABTS}^{+}$was produced by reaction of $8 \mathrm{mM} \mathrm{ABTS} \mathrm{(87.7} \mathrm{mg} \mathrm{in} 20 \mathrm{~mL}$ of distilled water) and $3 \mathrm{mM}$ potassium persulfate $(0.0162 \mathrm{~g}$ in $20 \mathrm{~mL}$ distilled water) in a $1: 1(\mathrm{v} / \mathrm{v})$ ratio.

The mixture was then incubated in the dark at room temperature for 12-16 hours. This ABTS + solution was diluted with methanol so as to obtain a solution whose absorbance was $0.7 \pm 0.02$ at $734 \mathrm{~nm}$. Thus, a test sample of $3.9 \mathrm{~mL}$ of this diluted $\mathrm{ABTS}^{+}$solution was added to $100 \mu \mathrm{L}$ of the compound to be tested.

After stirring, the mixture was incubated for 6 minutes in the dark $\left(\mathrm{T}=30 \pm 2{ }^{\circ} \mathrm{C}\right)$. The residual absorbance of the ABTS + radical was then measured at $734 \mathrm{~nm}$ on the UV-visible spectrophotometer and should be between $20 \%$ and $80 \%$ of the absorbance of the blank. The trials were carried out in triplicate and the results were expressed in $\mu \mathrm{mol}$ Trolox equivalent per liter of extract $(\mu \mathrm{mol} \mathrm{TE} / \mathrm{L})$. 
A calibration line was made with the following Trolox concentrations : $0.375 \mu \mathrm{M} ; 0.5 \mu \mathrm{M} ; 0.625 \mu \mathrm{M} ; 1 \mu \mathrm{M}$; $1.125 \mu \mathrm{M}, 1.375 \mu \mathrm{M}$ and $1.5 \mu \mathrm{M}$ and the inhibition rate $(\% \mathrm{I})$ of $\mathrm{ABTS}^{+}$was expressed as follows:

$\% \mathrm{I}=[(\mathrm{A} 0-\mathrm{Abs}$ extract $) / \mathrm{A} 0] \times 100$

$\mathrm{A} 0=$ diluted ABTS absorbance.

Abstrand $=$ absorbance ABTS diluted + sample

This line allowed to express the antioxidant activity of the various extracts as follows: Concentration or Reductive Capacity of the cation ABTS $(\mu \mathrm{M}$ eq Trolox $)=(\% \mathrm{I} x \mathrm{fd}) /(4.99 \times 10)$

\subsubsection{Study of the antiradical activity by the trapping of the DPPH radical}

The antiradical activity of extracts of leaves of Erythrococca anomala was measured by the 2,2'diphenyl-1-picrylhydrazyl (DPPH) test according to the Parejo method [16] with some modifications. A range of concentrations $(0-200 \mu \mathrm{g} / \mathrm{mL})$ of aqueous and hydroethanolic extracts of leaves of Erythrococca anomala or Quercetin (reference antioxidant) is prepared in ethanol / water (70/30) (v/v).

A volume of $100 \mu \mathrm{L}$ of this solution is mixed with $3.9 \mathrm{~mL}$ of DPPH $(70 \mu \mathrm{M})$ prepared in methanol After homogenization, the mixture is incubated at room temperature $\left(25^{\circ} \mathrm{C}\right.$.) to Shelter from light. After 15 minutes of incubation, the absorbance is read at $517 \mathrm{~nm}$ against a "white" which contains only methanol.

The percentage inhibition of the DPPH radical is calculated according to the following equation :

Inhibition of DPPH $(\%)=(\mathrm{A} 0$ - Aextrait $) / \mathrm{A} 0) \mathrm{x} 100$.

$\mathrm{A} 0=$ absorbance $($ control)

A extract $=$ absorbance $($ extract $)$

$\mathrm{IC}_{50}$, which is the concentration of leaf extract or Quercetin responsible for $50 \%$ inhibition of DPPH radicals, is determined by projection from $50 \%$ on the graph representing the percentage inhibition of DPPH as a function of the concentrations Extracts and Quercetin. (\% DPPH inhibition $=\mathrm{f}$ (extract concentrations).

\subsubsection{Study of antioxidant activity in vivo}

\subsubsection{Induction of oxidative stress by carrageenan}

Oxidative stress was produced by injection of carrageenan at the left hind paw of rats. Wistar rats were fasted for 16 het were weighed before being used for the experiment. They were subdivided into 5 groups of 6 rats with an average weight of $130 \mathrm{~g}$. Group I received saline (control), group II received vitamin C (reference molecule), groups III, IV and V respectively received aqueous and hydroethanolic extracts from the leaves of Erythrococca anomala (200 $\mathrm{mg} / \mathrm{Kg}$ body weight) and $\mathrm{NaCl}+$ carrageenan. All the animals received $1 \mathrm{~h}$ after treatment $0.2 \mathrm{ml}$ of $1 \%$ carrageenan suspension in the left hind foot subplant area. The blood of the rats is taken 5 hours later in heparinized tubes. This blood is then centrifuged and the serum is used for the study of antioxidant activity.

\subsubsection{Determination of TBARS}

The TARSB (Thiobarbituric Acid Reactive Substances) assay in aqueous and hydroethanolic extracts of the leaves of Erythrococca anomala was carried out according to the Satho method [17]. To prepare the serum proteins, $2.5 \mathrm{~mL}$ TCA $20 \%(\mathrm{~m} / \mathrm{V}$ ) was added to $0.5 \mathrm{~mL}$ of rats serum, which was centrifuged at $1500 \mathrm{~g}$ for $10 \mathrm{~min}$. Next, $2.5 \mathrm{~mL}$ of sulfuric acid and $2 \mathrm{Ml}$ TBA $(0.2 \%)$ were added to the sediment. This mixture reaction was then shaken and then shaken and then incubated for 30 minutes in a boiling bath. After addition of $4 \mathrm{~mL}$ of $\mathrm{n}$-butanol, the solution was centrifuged, cooled and the absorbance of the supernatant read at 352 $\mathrm{nm}$. The calibration curve was obtained using different concentrations of $1,3,3$ tetramethoxypropane $(0.0$, $1.875,2.380,4.760,9.530,19.050,38.110)$ as the standard for determining the concentration of TBA-MDA adducts in the sample.

\subsubsection{Determination of total antioxidant power : the FRAP test}

The determination of the total antioxidant power of the aqueous and hydroethanolic extracts of leaves of Erythrococca anomala present in the serum according to the method of Benzie and Strain [18] is based on the measurement of the ability to reduce the $\mathrm{Fe}^{3+}$ ion to $\mathrm{Fe}^{2+}$ ion by the FRAP test (FerricReducing Ability of Plasma). The FRAP test measures the variation in absorbance at $593 \mathrm{~nm}$ of a blue complex (FeIItripyridyltriazine (TPTZ) by the action of electron-donating antioxidants. The FRAP reagent is composed of 300 mmol.L-1 of Acetate buffer, $\mathrm{pH}=3.6,10 \mathrm{mmol} . \mathrm{L}-1 \mathrm{TPTZ}$ in $40 \mathrm{mmol} \cdot \mathrm{L}^{-1} \mathrm{HCl}$ and $20 \mathrm{mmol} \cdot \mathrm{L}^{-1} \mathrm{FeCl}_{3}, 6 \mathrm{H}_{2} \mathrm{O}$ in the ratio of 10: 1: 1 .

Thus, $10 \mu \mathrm{L}$ of serum was added to $300 \mu \mathrm{L}$ of FRAP reagent (freshly prepared and preheated at $37^{\circ}$ C.) in a test tube. After $10 \mathrm{~min}$ incubation at $37^{\circ} \mathrm{C}$, the absorbance of the blue complex is read against a blank ( $300 \mu \mathrm{L}$ of FRAP reagent $+10 \mu \mathrm{L}$ of distilled water) at $593 \mathrm{~nm}$. The $\mathrm{Fe}^{2+}$ standard solutions in the concentration range from 100 to 1000 mmol- $\mathrm{L}^{-1}$ were prepared from ferrous sulfate $\left(\mathrm{FeSO}_{4}, 7 \mathrm{H}_{2} \mathrm{O}\right)$ in distilled water. The data were expressed in mmol of ferric ions reduced to the ferrous form per liter (FRAP value). 


\subsection{Statistical Analysis}

The values expressed as mean \pm SEM from 6 animals. The results were subjected to statistical analysis by using one way ANOVA followed by Dunnett's test to significant, $\mathrm{p}$ values less than 0.05 were considered significant.

\section{Results}

3.1.1. Quantification of antioxidant compounds (phenols and flavonoids) in vitro of aqueous and hydroethanolic extracts of leaves of Erythrococca anomala

The amounts of total polyphenol in the aqueous and hydroethanolic extracts of Erythrococca anomala leaves are shown in Table 1. The aqueous extract had more phenols $(85 \pm 1.44 \mathrm{mg}$ EAG / g) and flavonoids $(28.33 \pm 0.33 \mathrm{mg} \mathrm{EQ} / \mathrm{g})$ than the hydroethanolic extract $(69.17 \pm 0.83 \mathrm{mg}$ EAG / g) of phenols and flavonoids $(23.23 \pm 0.83 \pm 0.33 \mathrm{mg} \mathrm{EQ} / \mathrm{g})$. The polyphenolic compounds were present both in the aqueous extract and in the hydroethanolic extract.

Table 1 : Total polyphenol and total flavonoid content of the aqueous and hydroethanolic extracts of the leaves of Erythrococca anomala.

\begin{tabular}{|l|c|c|}
\hline Extracts & Content phenols gallic acid (mg EAG / g) & $\begin{array}{l}\text { Flavonoid Content } \\
\text { Quercetin (mg EQ / g) }\end{array}$ \\
\hline Aqueous extracts & $85 \pm 1.44$ & $28.33 \pm 0.33$ \\
\hline Hydroethanol extract & $69.17 \pm 0,83$ & $23.23 \pm 0.83$ \\
\hline
\end{tabular}

Values represent the average $\pm \mathrm{SD},(\mathrm{n}=3)$; (EAG) Gallic acid equivalent; (EQ) Equivalent quercetin.

3.1.2. Reductive capacity of the $\mathrm{ABTS}^{+}$ion of aqueous and hydroethanolic extracts of the leaves of Erythrococca anomala.

The antioxidant activities of the extracts are given in Table 2. The extract has an activity equal to $34.45 \pm 3.13$ $\mu \mathrm{mol}$ Trolox equivalent / $\mathrm{L}$ whereas that of the hydroethanolic extract of $26.82 \pm 1.73 \mu \mathrm{mol}$ Equivalent Trolox / $\mathrm{L}$. The reducing capacity of the $\mathrm{ABTS}^{+}$ion of the aqueous extract is greater than that of the hydroethanolic extract.

Table 2 : Reductive capacity of the ABTS ion of the aqueous and hydroethanolic extracts of the leaves of Erythrococca anomala.

\begin{tabular}{|l|c|}
\hline Extracts & Antioxidant activity expressed in $\square$ mol Trolox equivalent / L \\
\hline Aqueous extracts & $34.45 \pm 3.13$ \\
\hline Hydroethanolic extract & $26.82 \pm 1.73$ \\
\hline
\end{tabular}

Values represent the average $\pm S D,(n=3)$.

\subsubsection{Anti-freeze activity by the DPPH test}

The $\mathrm{IC}_{50}$ values of the extracts determined graphically by the linear regressions of the graphs lined against that of quercetin $(5.75 \mu \mathrm{g} / \mathrm{mL})$ are respectively $10.5 \mu \mathrm{g} / \mathrm{mL}$ and $21.5 \mu \mathrm{g} / \mathrm{mL}$ for aqueous and hydroethanolic extract Fig 1.

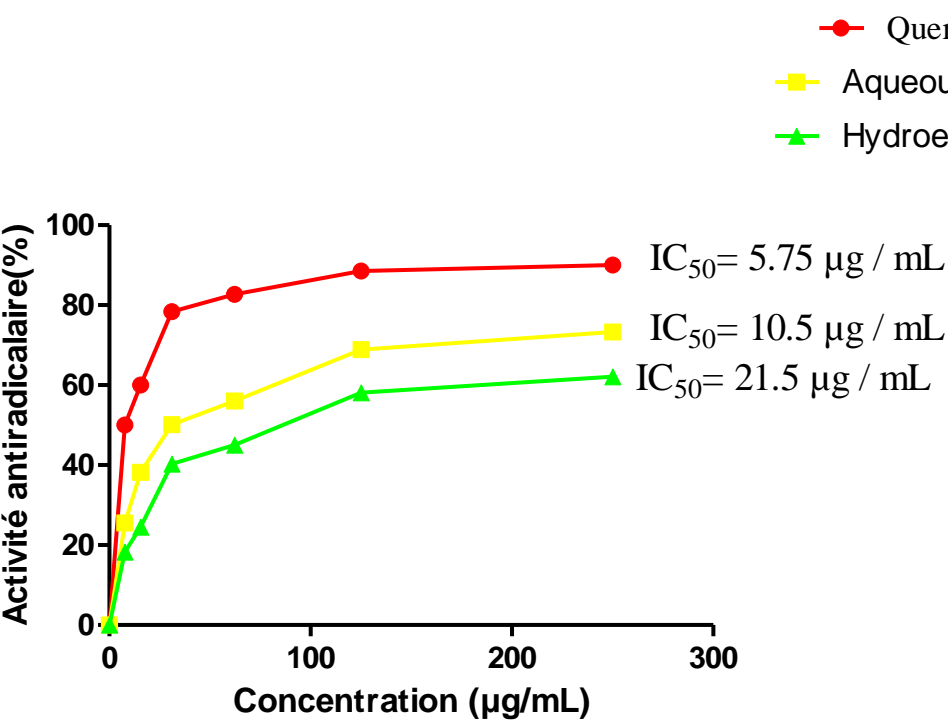

Fig 1 : Anti-radical activity of aqueous and hydroethanolic extracts of leaves of Erythrococca anomala 


\subsection{Evaluation of the in vivo antioxidant activity of aqueous and hydroethanolic extracts of leaves of Erythrococca anomala : Total antioxidant power by TBARS and FRAP tests}

The values obtained with the TBARS and FRAP test are shown in Table 3. The values of the aqueous extract and the vitamin $\mathrm{C}$ are very high compared to the $\mathrm{NaCl}$ control with the TBARS test with $\mathrm{p}<0.001$.

More over with the test of FRAP and TBARS the antioxidant power of the vitamin $\mathrm{C}$ and the aqueous extract is much higher compared to the control. However vitamin $\mathrm{C}$ recorded the greatest value with both methods.

Table 3 : In vivo antioxidant activity of leaves of Erythrococca anomala by TBARS and FRAP tests

\begin{tabular}{|l|c|c|}
\hline Extracts & TBARS $(\%)$ & FRAP $(\boldsymbol{\mu m o l}$ de fer II/L) \\
\hline NaCl + carrageenan & $25.83 \pm 0.98$ & $3.8 \pm 0.75$ \\
\hline Hydroethanolic extract & $22.67 \pm 0.81$ & $7.2 \pm 0.75$ \\
\hline Aqueous extracts & $9.16 \pm 1.16^{* * *}$ & $10 \pm 1.00^{* * *}$ \\
\hline Vitamine C & $7 \pm 1.03^{* * *}$ & $12 \pm 0.75^{* * *}$ \\
\hline NaCl & $8.5 \pm 0.83$ & $6.3 \pm 0.52$
\end{tabular}

Each value is mean \pm SEM, N= 6 rats, the data was analyzed by using One Way ANOVA followed by Dunnett's test $* * \mathrm{p}<0.001$, where Extracts and control were compared with $\mathrm{NaCl}$.

\section{Discussion}

Among the recognized biological potentialities of plants, antioxidant activity is of growing interest because of the important roles played by antioxidant compounds found in plants, in the treatment and prevention of oxidative dysfunction diseases [19, 20,21].

The spectrophotometric method was used in this study to quantify the polyphenols. The antioxidant activity was evaluated by trapping of free radicals such as the method of FRAP, TBARS, and the method using the DPPH radical and the cationic radical $\mathrm{ABTS}^{+}$.

Aqueous and hydroethanolic extracts (200 mg / kg bw) showed significant antioxidant activities in vitro by inhibition of the DPPH radical and reduction of ABTS ${ }^{+}$cation in comparaison with vitamin $\mathrm{C}$ and quercetin.

In addition, tests of FRAP and TBARS in vivo revealed the reductive and inhibitory activities of the two extracts in comparison with that of vitamin C. The antioxidant capacity of plant extracts is largely dependent on the composition of these extracts. The reducing power of leaves of Erythrococca anomala is probably due to the presence of hydroxyl groups in the polyphenolic compounds (phenols and flavonoids) which can serve as electron donors, therefore antioxidants are considered oxidant reducing agents and inhibitors

[22]. A few previous studies have also shown that the reducing power of a compound can serve as a significant indicator of its potential antioxidant activity $[\mathbf{2 3 , 2 4}]$ The agreement between the DPPH, ABTS ${ }^{+}$, FRAP and TBARS radical tests is that the four tests retain the aqueous extract as a powerful antioxidant.

Water is a solvent which can extract the majority of chemical constituents such as water-soluble and water-soluble polyphenolic compounds of anti-free radical properties.

\section{Conclusion}

The evaluation of the antioxidant activity of the aqueous and hydroethanolic extracts of the leaves of Erythrococca anomala par the in vitro tests of the DPPH radical, $\mathrm{ABTS}^{+}$cation and in vivo the tests of FRAP, TBARS demonstrated the reducing power and inhibitors of these extracts. In this study, aqueous and hydroethanolic extracts appear to be of real and potential interest by their antioxidant activities that have been established both in vitro and in vivo. By these tests, the aqueous excipient revealed the greatest antioxidant power close to those of quercetin and ascorbic acid.

The study of the polyphenolic composition of the various extracts elucidates the cause of the great antioxidant and antiradical activity of the aqueous extract relative to the hydroethanolic extract.

\section{Ethical approval}

The experimental procedures and protocols used in this study were approved by the Ethical Committee of Health Sciences, University Félix Houphouet-Boigny. These guidelines were in accordance with the European Council Legislation 87/607/EEC for the protection of experimental animals. All efforts were made to minimize animal suffering and reduce the number of animals used.

\section{References}

[1]. Suhaj, M., 2006. Spiceantioxidants isolation and theirantiradical activity : areview.Journal of Food Composition and Analysis 19, 531-537.

[2]. Tadhani, M.B., Patel, V.H., et Subhash, R., 2007. In vitro antioxidant activities of Steviarebaudiana leaves and callus. Journal of Food Composition and Analysis. 20, 323-329.

[3]. Koechlin-Ramonatxo C. (2006)Oxygen, oxidative stress and antioxidantsupplementation, or another way for nutrition in respiratory diseases. Nutrition Clinique et Métabolique. 20, 165177. 
[4]. Dugas A. J., Castaneda-Acosta J. Bonin G.C, Price K.H. Fisches N.H. et Winston G.W. (2000). Evaluation of the total peroxyl radical scavengingcapacity of flavonoids: structure activity relationships. Journal of Naturalproduct. 63, 31-327

[5]. Huang, D., Ou, B., Prior, R. L. (2005) The chemistrybehindantioxidantcapacityassays. Journal of Agricultural and Food Chemistry. 53, 1841-1856.

[6]. Marc Fr., Davin A., Deglène-Benbrahim L., et Ferrand C. (2004) Méthodes d'évaluation du potentiel antioxydant dans les aliments. Erudit, M/S : médecine sciences. 20(4), 458-463.

[7]. Sanchez-Moreno C. (2002)Methods used to evaluate the free radical scavenging activity in foodsand biologicalsystems. Food Science and Technology International. 8(3), 121-137.

[8]. Miezan BAP, Okpekon AT, Yapi HF, Bony FN, Gbassi G, Assi YJ. Chemical component and acute toxicity study of Erythrococca anomala (Euphorbiaceae). Asian Journal of Biomedical and Pharmaceutical Sciences. 2016 ; 6(57) :4-8. 5.

[9]. Oladele GM, Abatan MO, Olukynle JO, Okediran BS. Anti-inflammatory and analgesic effect of aqueous leafextracts of Gomphrenacelosioides and Momordicacharinda. J Nat. Sat. Sci. Engr. Tech. $2009 ; 8(2): 1-8.6$.

[10]. Patrice MBA, Yapi HF, Opkekon AT, Bony FN, Kouakou-Siransy G, Kouakou YébouéKF. Evaluation of anti-inflammatory activities of Erythrococca anomala aqueous and ethanolic extracts from leaves in rat. 14(2) : 1-7, 2016 ; IJBCRR.28385.

[11]. Adjanohoun EJ, Ake-Assi L. Contribution au recensement des plantes médicinales de Côte d'Ivoire. Centre National de Floristique de l'Université Nationale de Côte d'Ivoire, Tome 1, 23-30. Lavoisier, Paris. 1979 ; 895.

[12]. Guédé FG. (1990) Extraction of mansoninfromMansoniaaltissimaas cardiovascular agent (patent application). Ministère de la Recherche Scientifique, Côte d'Ivoire. 35 pp.

[13]. Wood J. E., Senthilmohans . T., Peskin A. V., 2002. Antioxidant activity of procyanidin-containing plant extracts at different pHs. Food Chemistry, T.77, p.155-161.

[14]. Marinova D., Ribarova F. et Atanassovava. M., 2005.Total phenolics in bulgarian Fruits and vegetables. Journal of the University of Chemical Technology and Metallurgy, T.40, N³, p.255-260.

[15]. Choong. C., Van-DenT. T., Roger F., Roger.MCF. L., 2007. Antioxidant activities, phenolic and beta-carotene contents of sweet potato genotypes with varying flesh colours.FoodChemistry103 (3): 829-838.

[16]. Parejo I., Codina C., Petrakis C. et Kefalas P., 2000. Evaluation of scavenging activity assessed by Co (II)/EDTA-induced luminal chemilunes-cence and DPPH (2,2-diphényl-1-pycryl-hydrazyl) free radical assay. JPharmacolToxicol Method, 44 :507-512.

[17]. Satho K. (1978). Serum lipid peroxydation in cerebrovasculardisordersdeterminate by a new colorimetricmethod. Clin. Chim. Acta, $90: 37-43$.

[18]. Benzie I.F.et StrainJ.J.(1996). Ferricreducingability of plasma (FRAP) as a measure of antioxydant power : The FRAP assay. Anal. Biochim., 239 :70-76.

[19]. Cole, G.M., Lim, G.P., Yang, F., Teter, B., Begum, A., Ma, Q., Harris-White, M.C. et Frautschy, A. 2005. Prevention of Alzheimer'sdisease: omega-3 fattyacid and phenolicantioxidant interventions. Neurobiol. Aging, 26: S133 - S136.

[20]. Riboli, E. et Norat, T. 2003. Epidemiologicevidence of the protective effect of fruit and vegetables on cancer risk. Am. J. Clin. Nutr., 78: 559S - 569S.

[21]. Liu, R.H. 2003. Healthbenefits of fruit and vegetables are from additive and synergisticcombinations of phytochemicals. Am. J. Clin. Nutr., 78: 517S -520S.

[22]. Siddhuraju P.et Becker K. (2007) The antioxidantand free radical scavenging activities of processedcowpea (Vignaunguiculata (L.) Walp.) seed extracts. Food Chemistry. 101(1), 10-19

[23]. Jeong S.M., Kim S.Y., Kim D.R., Jo S.C., Nam K.C., Ahn D.U., et Lee S.C. (2004) Effects of heat treatment on the antioxidant activity of extracts from citrus peels. Journal of Agriculture and Food Chemistry. 52, 3389-3393.

[24]. Kumaran, A. etKarunakaran, R.J. (2007) In vitro antioxidant activities of methanol extracts of five Phyllanthus species from India. Lebensmittel-Wissenschaft und Technologie. 40, 344-352. 